\begin{tabular}{|c|c|c|c|}
\hline \multirow{3}{*}{$\begin{array}{r}\text { Case Reports in } \\
\text { Gastroenterology }\end{array}$} & \multicolumn{2}{|c|}{ Case Rep Gastroenterol 2017;11:17-22 } & \multirow[b]{2}{*}{$\begin{array}{l}\text { Karger } \\
\text { Open access }\end{array}$} \\
\hline & $\begin{array}{l}\text { DOI: 10.1159/000455187 } \\
\text { Publisnea onmine: January 27, } 2017\end{array}$ & $\begin{array}{l}\text { (C) } 2017 \text { The Author(s) } \\
\text { Published by S. Karger AG, Basel } \\
\text { www.karger.com/crg }\end{array}$ & \\
\hline & $\begin{array}{l}\text { This article is licensed under the } \\
\text { International License (CC BY-NC) } \\
\text { Usage and distribution for commer }\end{array}$ & $\begin{array}{l}\text { mons Attribution-NonCommercia } \\
\text { rger.com/Services/OpenAccessLice } \\
\text { quires written permission. }\end{array}$ & \\
\hline
\end{tabular}

\title{
Simultaneously Diagnosed and Successfully Treated Rectovaginal and Vesicovaginal Fistulae after Low Anterior Resection with Concomitant Resection of Female Genitalia
}

\author{
Chisato Takagi Hideo Baba Kazuo Yamafuji Atsunori Asami \\ Kaoru Takeshima Nobuhiko Okamoto Hidena Takahashi \\ Kiyoshi Kubochi \\ Department of Surgery, Saitama City Hospital, Saitama City, Japan
}

\section{Keywords}

Vesicovaginal fistula $\cdot$ Rectovaginal fistula $\cdot$ Rectal cancer $\cdot$ Omental flap

\begin{abstract}
Rectovaginal fistula (RVF) and vesicovaginal fistula (VVF) are infrequent but distressing complications after pelvic surgery. However, their adequate treatment is not well described. Here, we simultaneously encountered and successfully treated RVF and VVF after radical surgery for rectal cancer. A 70-year-old woman underwent low anterior resection (LAR) combined with resection of the uterus, the bilateral adnexa, and the upper side of the vagina, as well as diverted ileostomy for rectal cancer. A month after the surgery, she developed urinary incontinence and underwent medical treatment, but her symptoms did not improve. Evaluation with contrast enema before stoma closure revealed the presence of RVF and VVF. We repaired the VVF and RVF via transabdominal and transperineal approaches. After 6 months, ileostomy was closed and the patient had no recurrence of cancer and fistula. In LAR with hysterectomy and resection of the vaginal wall, there is a risk of RVF and VVF. The excision and closure of the fistula tract and omental flap can be effective to treat both fistulae.
\end{abstract}


Takagi et al.: Simultaneously Diagnosed Rectovaginal and Vesicovaginal Fistulae

\section{Background}

An aggressive surgical approach is the key to cure rectal cancer that invades the uterus and the vagina. However, surgery is accompanied by a high risk of postoperative complications. Rectovaginal fistula (RVF) and vesicovaginal fistula (VVF) are infrequent postoperative complications after surgery for rectal cancer. Moreover, they are among the most distressing complications of pelvic surgery because they worsen patients' ability to perform activities of daily living. Although several procedures to treat these complications have been advocated, the most adequate method depends on individual situations [1].

Here, we report a case of simultaneously diagnosed and successfully treated RVF and VVF that occurred after low anterior resection (LAR) combined with resection of female genitalia.

\section{Case Presentation}

A 70-year-old woman presented with a 1-month history of hematochezia and exertional dyspnea. Complete blood count revealed severe anemia (Hb $3.5 \mathrm{~g} / \mathrm{dL}$; normal range 11.5$15.0 \mathrm{~g} / \mathrm{dL}$ ) and, as a result, she received blood transfusions. Colonoscopy revealed the presence of an $\mathrm{Rb}$ rectal cancer, the lower edge of which was located $3 \mathrm{~cm}$ above the upper edge of the anal canal. This lesion narrowed the rectum such that the colonoscope could not pass through. Images obtained by contrast-enhanced computed tomography and gadoliniumenhanced magnetic resonance imaging suggested that the tumor had invaded the uterine cervix and upper vaginal wall.

We performed LAR combined with resection of the uterus, bilateral adnexa, and upper side of the vagina, diverted ileostomy following transverse colostomy, and 6 courses of chemotherapy, which consisted of capecitabine and oxaliplatin. Colorectal anastomosis was performed with a double stapling technique. The vaginal stump was closed with an interrupted suture using an absorbable suture. The patient's postoperative course was uneventful, and she was discharged on postoperative day 10.

A month after the surgery, she developed urinary incontinence. Because urinary incontinence occurred all day and night, she also suffered from insomnia. She was initially diagnosed with overactive bladder and prescribed mirabegron, but her symptoms did not improve. Four months after LAR, a contrast enema was performed for evaluation of colorectal anastomosis before ileostomy closure. Contrast media reached the residual vagina and bladder from the colorectal anastomosis site, which suggested that RVF and VVF were simultaneously present (Fig. 1). The RVF was located near the colorectal anastomosis site. Cystoscopy and retrograde cystography revealed that the VVF was located at the trigone of the bladder (Fig. 2). Contrast media in retrograde cystography easily flowed to the remnant vagina. We thought that these findings might explain her urinary incontinence. The RVF could be symptomatic after stoma closure without repairing it. We decided to repair both fistulae.

Under general anesthesia, the patient was placed in the lithotomy position, and the RVF $(0.5 \mathrm{~cm}$ in diameter) and VVF (1.5 cm in diameter) were identified using a colposcope and digital examination. A urinary catheter was inserted. The VVF was approached via the transabdominal route. Laparotomy was performed, and a sagittal incision was made from the dome of the bladder down to the fistulous tract, which was near the trigone of the bladder (Fig. 3a). To avoid injuring the urinary tract, we placed urethral catheters bilaterally. The 
Takagi et al.: Simultaneously Diagnosed Rectovaginal and Vesicovaginal Fistulae

fistulous tract of the VVF was completely excised. We closed the excised space of the VVF by suturing the bladder wall, followed by suturing the anterior wall of the vagina with a vaginal approach with a delayed absorbable suture. Subsequently, the fistulous tract of the RVF was completely excised via a vaginal approach (Fig. 3b). We closed the excised space of the RVF by suturing the rectum wall, followed by suturing the posterior wall of the vagina with a delayed absorbable suture. Finally, the omental flap was made by cutting the omentum from the right, interposing it between the vagina and bladder, and placing it over the repaired RVF to prevent leakage and recurrence of the fistula (Fig. 3c).

After the operation, the patient was discharged and had an uneventful postoperative course. The urinary catheter was removed and her urinary incontinence was improved 2 months after the repair of the fistulae. Six months after the repair of the fistulae, no recurrence of the fistulae was seen on contrast media enema and retrograde cystography. Following these examinations, the ileostomy was closed. Six months after ileostomy closure, the patient had no recurrence of cancer or fistula.

\section{Discussion}

As shown in this case, RVF and VVF can be discovered simultaneously after LAR with hysterectomy and partial vaginectomy. RVF and VVF occur after anterior resection and hysterectomy, respectively. Although they are infrequent postoperative complications, their incidence may be higher after LAR with hysterectomy and partial vaginectomy.

The incidence of RVF after LAR has been reported to be 2.9-9.9\% [2-4]. These studies also reported the risks of developing RVF after LAR. While the study designs and reported risk factors were different among these studies, advanced stage and low anastomosis level seem to be risk factors. While hysterectomy alone was not an independent risk factor [2, 3], concomitant hysterectomy and partial vaginectomy was reported to be a risk factor for postoperative RVF after LAR [2].

VVF is also a rare complication after hysterectomy, the occurrence of which was reported to be $0.1-2.6 \%$ [5-7]. In particular, the occurrence of VVF was reported to be higher in the case of radical hysterectomy [6]. Radical hysterectomy includes partial vaginectomy and was reported to cause ischemic damage and unrecognized visceral injury related to dissection of the vesicovaginal septum $[7,8]$. As in the present study, although no studies have reported the risk of developing VVF after surgery for rectal cancer, LAR with hysterectomy and resection of the vaginal wall can theoretically cause VVF.

While various surgical procedures for the treatment of RVF and VVF have been advocated, it is still not clear what the most appropriate method of repair is $[1,9,10]$. To the best of our knowledge, there are no reports in which RVF and VVF after LAR were simultaneously treated. This case also demonstrates that the RVF and VVF can be simultaneously treated with surgery. We repaired the VVF and RVF based on the same basic principles: excision of the fistula, closure of the excised space, and tissue coverage. In this case, a diverted stoma decreased local inflammation and improved the healing of perianal lesions. In addition, the RVF was small in size and was observed through the perineum. Thus, we repaired the RVF by using the transperineal approach. A similar method was used in a previous report [11]. The VVF was located near the trigone so that sagittal cystotomy could help identify the VVF and the trigone of the bladder and avoid urinary tract injury. Sagittal cystotomy with a bivalve technique was also beneficial to VVF excision $[12,13]$. Moreover, we thought that using an omental graft for tissue interposition contributed to the successful repair in the pre- 
Takagi et al.: Simultaneously Diagnosed Rectovaginal and Vesicovaginal Fistulae

sent case. Tissue interposition improved the success rate of VVF and RVF in other reports $[14,15]$. Similar to our report, another previous study reported that omentum interposition with a transabdominal approach was beneficial [13].

\section{Conclusion}

RVF and VVF are infrequent but serious postoperative complications, because they worsen patients' ability to perform activities of daily living. In LAR with hysterectomy and resection of the vaginal wall, the risk of RVF and VVF increases. The excision and closure of the fistula tract and omental flap can be effective to treat both complications.

\section{Statement of Ethics}

Written informed consent was obtained from the patient for publication of this case report and any accompanying images.

\section{Disclosure Statements}

All authors have no conflicts of interest to disclose.

\section{References}

1 Göttgens KW, Smeets RR, Stassen LP, Beets G, Breukink SO: The disappointing quality of published studies on operative techniques for rectovaginal fistulas. Dis Colon Rectum 2014;57:888-898.

-2 Kosugi C, Saito N, Kimata Y, Ono M, Sugito M, Ito M, et al: Rectovaginal fistulas after rectal cancer surgery: Incidence and operative repair by gluteal-fold flap repair. Surgery 2005;137:329-336.

-3 Matthiessen P, Hansson L, Sjödahl R, Rutegård J: Anastomotic-vaginal fistula (AVF) after anterior resection of the rectum for cancer - occurrence and risk factors. Colorectal Dis 2010;12:351-357.

-4 Nakagoe T, Sawai T, Tuji T, Nanashima A, Yamaguchi H, Yasutake T: Successful transvaginal repair of a rectovaginal fistula developing after double-stapled anastomosis in low anterior resection. Surg Today 1999;29:443-445.

-5 Liao CY, Tasi RSF, Ding DC: Gynecological surgery caused vesicovaginal fistula managed by Latzko operation. Taiwan J Obstet Gynecol 2012;51:359-362.

-6 Hilton P, Cromwell DA: The risk of vesicovaginal and urethrovaginal fistula after hysterectomy performed in the English National Health Service - a retrospective cohort study examining patterns of care between 2000 and 2008. BJOG 2012;119:1447-1454.

-7 Likic IS, Kadija S, Ladjevic NG, Stefanovic A, Jeremic K, Petkovic S, et al: Analysis of urologic complications after radical hysterectomy. Am J Obstet Gynecol 2008;199:644.e1-e3.

8 Karkhanis P, Patel A, Galaal K: Urinary tract fistulas in radical surgery for cervical cancer: the importance of early diagnosis. Eur J Surg Oncol 2012;38:943-947.

-9 Stamatakos M, Sargedi C, Stasinou T, Kontzoglou K: Vesicovaginal fistula: diagnosis and management. Indian J Surg 2014;76:131-136.

10 Kniery KR: Operative considerations for rectovaginal fistulas. World J Gastrointest Surg 2015;7:133.

-11 Yodonawa S, Ogawa I, Yoshida S, Ito H, Kobayashi K, Kubokawa R: Rectovaginal fistula after low anterior resection for rectal cancer using a double stapling technique. Case Rep Gastroenterol 2010;4:224-228.

12 Angioli R, Penalver M, Muzii L, Mendez L, Mirhashemi R, Bellati F, et al: Guidelines of how to manage vesicovaginal fistula. Crit Rev Oncol Hematol 2003;48:295-304.

13 Mangera A, Chapple C: Case discussion: vesicovaginal fistula following a total abdominal hysterectomy: the case for abdominal repair. Eur Urol Focus 2016;2:100-102. 
Takagi et al.: Simultaneously Diagnosed Rectovaginal and Vesicovaginal Fistulae

14 Eilber KS, Kavaler E, Rodríguez LV, Rosenblum N, Raz S: Ten-year experience with transvaginal vesicovaginal fistula repair using tissue interposition. J Urol 2003;169:1033-1036.

15 Debeche-Adams TH, Bohl JL: Rectovaginal fistulas. Clin Colon Rectal Surg 2010;23:99-103.

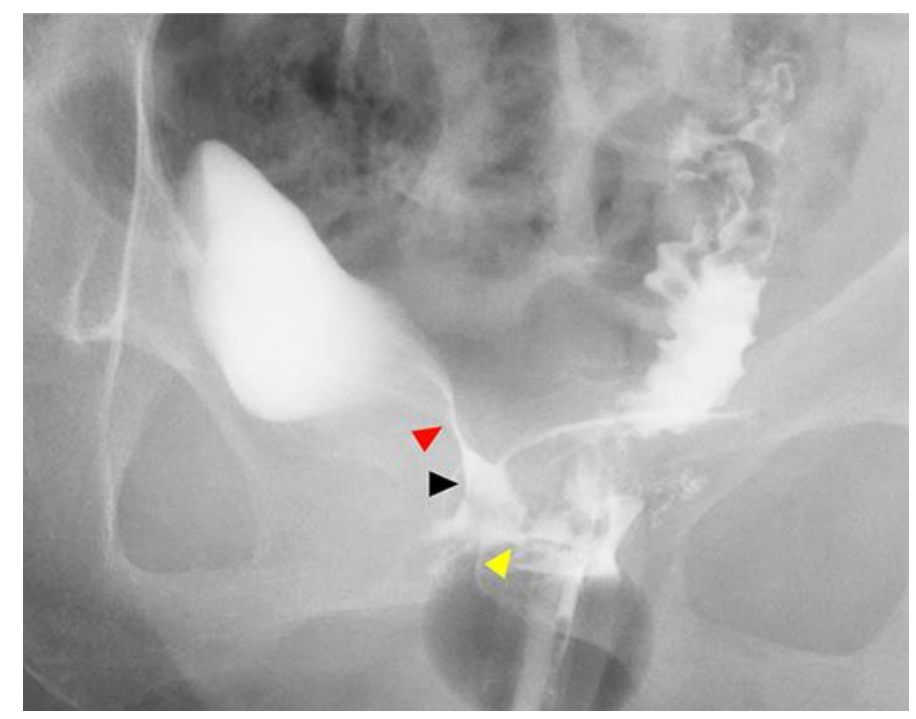

Fig. 1. Contrast enema fistula findings. The contrast enema demonstrated a rectovaginal fistula (yellow arrowhead) and a vesicovaginal fistula (red arrowhead). The remnant vagina was also shown (black arrowhead).

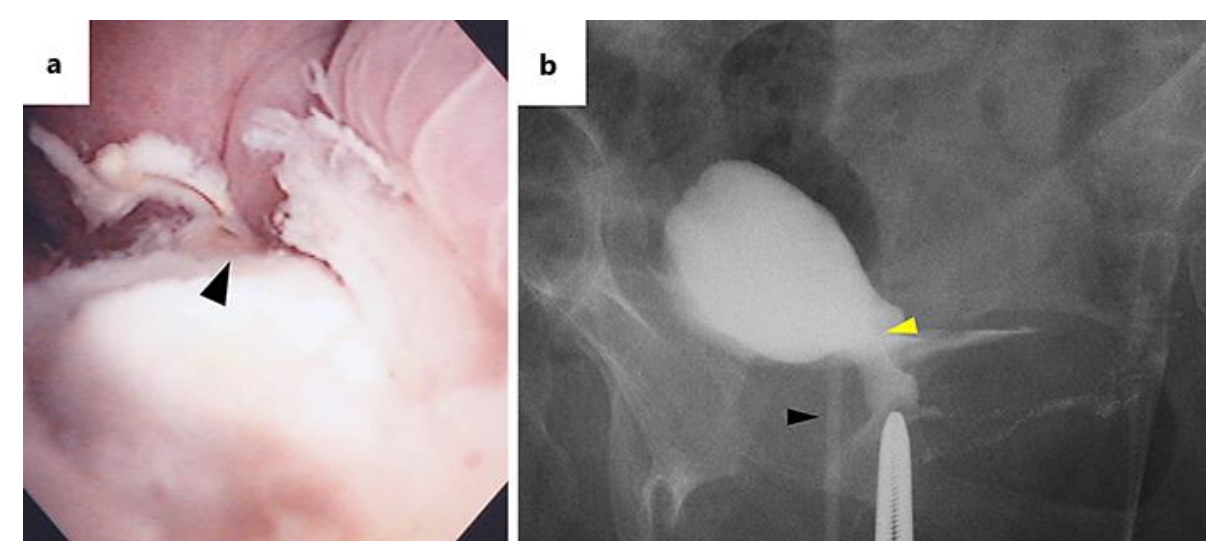

Fig. 2. Preoperative urological evaluation. a The black arrowhead shows a vesicovaginal fistula. b Retrograde cystography revealed that the vesicovaginal fistula (yellow arrowhead) was near the internal urethral orifice. A urethral catheter (black arrowhead) and a forceps point to the internal urethral orifice and the remnant vagina, respectively. 


\section{Case Reports in Gastroenterology
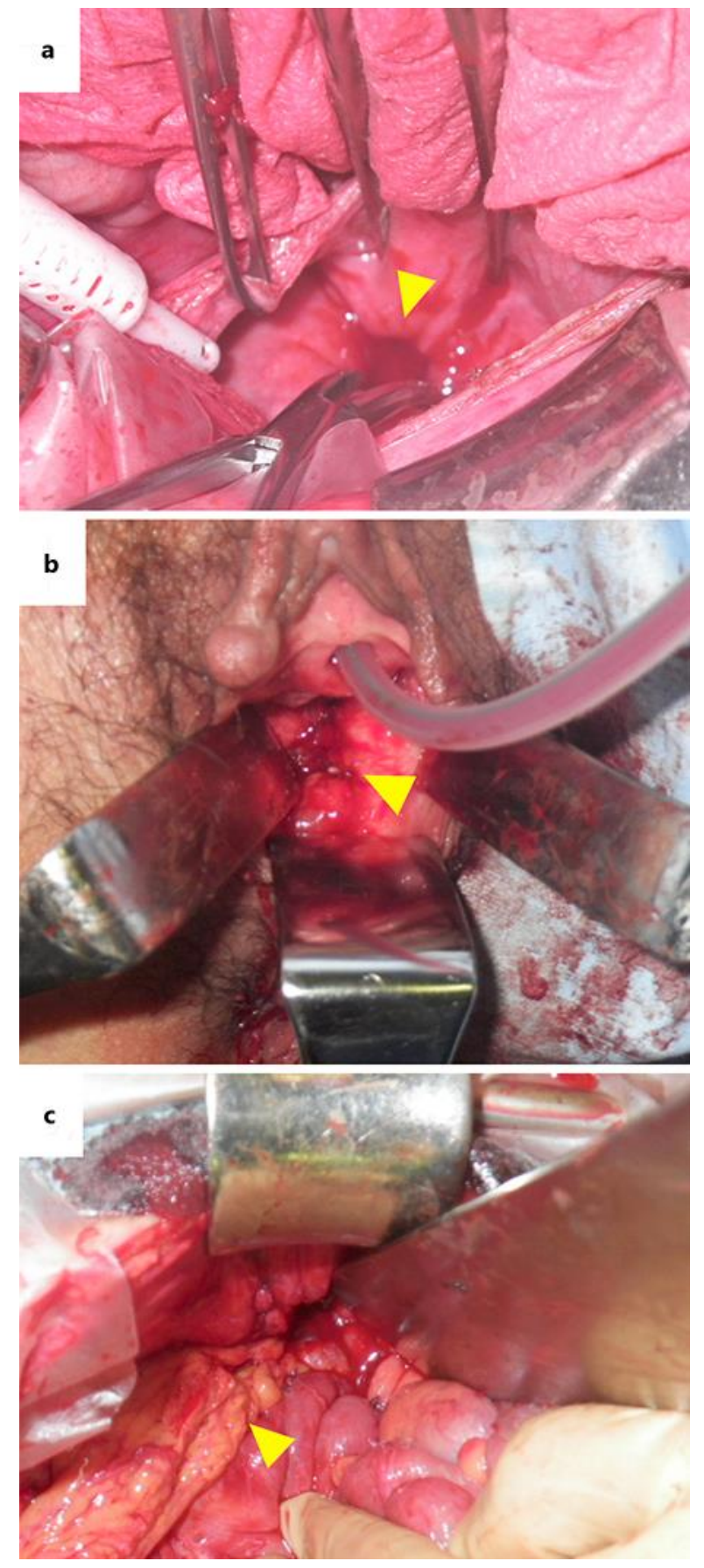

Fig. 3. Operative findings. a The bladder was incised sagittally from the dome, and a vesicovaginal fistula was detected (yellow arrowhead). b A rectovaginal fistula was detected in the vagina (yellow arrowhead). c An omental flap (yellow arrowhead) covered the bladder, vagina, and anastomosis of the rectum. 